\title{
A tutorial translation of the description of the historically first polymer drug conjugate and its in vivo evaluation
}

\section{Luxenhofer, Robert}

2020-09

Luxenhofer , R 2020 , ' A tutorial translation of the description of the historically first polymer drug conjugate and its in vivo evaluation ' , Zeitschrift für Naturforschung. Section C: A Journal of Biosciences , vol. 75 , no. 9-10 , pp. 303-311 . https://doi.org/10.1515/znc-2020-0077

http://hdl.handle.net/10138/331751

https://doi.org/10.1515/znc-2020-0077

acceptedVersion

Downloaded from Helda, University of Helsinki institutional repository.

This is an electronic reprint of the original article.

This reprint may differ from the original in pagination and typographic detail.

Please cite the original version. 


\section{A tutorial translation of the description of the historically first polymer drug conjugate and its in vivo evalution}

\section{Preamble}

Polymer-drug conjugates have been intensively investigated for several decades, and even though their clinical success still lags behind the promise many researchers have placed in them, they are a mainstay in the fields of polymer therapeutics or nanomedicine. For many in the field, the seminal perspective paper by Helmut Ringsdorf from 1975 marks the beginning of this field of research. With more than one thousand citations, this paper has indubitably affected and inspired generations of researchers in the field, including the author of this translation. However, it is not the first paper describing the concept of polymer-drug conjugates. Some twenty years earlier, Horst Jatzkewitz described in two outstanding papers probably the historically first polymer-drug conjugates, detailed its synthesis, characterization and even first in vivo experiments. The results, carefully re-interpreted through the eyes of a scientist of the $21^{\text {st }}$ century, clearly highlight several issues that need to be taken into consideration when designing polymer-drug conjugates. However, despite the pioneering nature of this paper, it is all but forgotten by the scientific community. In the author's opinion, Horst Jatzkewitz and these papers clearly did not receive the attention and praise they deserve. Whether this was because this paper was clearly ahead of it's time, or because it was published in German language, or for some other reason, we cannot know. However, this paper is, in my opinion, an excellent piece of work that should be known more widely and available to students and experts worldwide, which is why the author decided to translate it. Also, to give some more context and also to help understand some outdated terms or concepts, additional comments and explanations are added throughout. I hope that this will help for these papers to receive the attention I believe they deserve.

\section{On the introduction of physiologically active substances into a colloidal plasma expander Introduction of a mezcalin-peptide conjugate into poly(vinyl pyrrolidin)}

\section{Horst Jatzkewitz}

Klinisches Institut der Deutschen Forschungsanstalt für Psychiatrie, München, Germany Hoppe-Seyler's Zeitschrift für physiologische Chemie 1954, 297, (1), 149-156.

Mezcaline, applied to healthy humans, is well-known to exhibit psychic changes similar to those found in some psychoses. The similarity in its psychological effect is in accordance with the similarity in the chemical structure of mezcaline and that of biogenic amines. This fact led to a theory of formation of endogenic psychoses(1) and led to the investigation on the behavior of mezcaline in the organism(2).

Block and co-workers found that mezcaline is incorporated into liver proteins. Therefore, the organism is capable to synthesize amineproteins and, how was also established by $\operatorname{Block}(3,4)$, degrade it(3).

Box 1: Block and co-workers found, using ${ }^{14} \mathrm{C}$ labelled mescaline, that the molecule was incorporated covalently into proteins in the liver after injection. The mescaline-modified liver protein was therefore termed amineprotein (original: aminprotein). Hydrolysis of the protein yielded again mescalin.

Considering the chemical structure of amineproteins (Box 1), one might expect a mezcaline amidation of the acidic amino acids (glutamic acid and aspartic acid) or the C-terminus of the peptide chain.

It is the purpose of the present work to produce such a mezcaline-peptide and a mezcaline-protein like substance and to investigate their degradation in vivo and in vitro. Hereby, we understand as a mezcalinprotein like substance the synthetic introduction of a mezcaline peptide derivative (glycyl-L-leucylmezcaline) into the blood plasma expander polyvinylpyrrolidon (PVP, Box 2). The accordingly modified PVP shall at the same time serve as a model for a novel class of potentially therapeutically important depot substances ${ }^{1}$.

\footnotetext{
${ }^{1}$ Several decades ahead of the field, Jatzkewitz clearly understood the potential of polymer-drug conjugates!
} 
The plasma expander called "Persiton" contains PVP of a molar mass of about $30 \mathrm{~kg} / \mathrm{mol}$. Macromolecules of a size of $50-60 \mathrm{~kg} / \mathrm{mol}$ can be retained in the organism over months or years ${ }^{2}$ and may, due to their special binding capability for certain physiologically active compounds as depots $(5)^{3}$. However, it also must be possible to obtain a depot effect by covalently binding physiologically active substances by an enzymatically cleavable linker to PVP. This is described in the following for a PVP-glycyl-L-leucyl-mezcalin conjugate. Maybe, this allows the access of a depot form of a substance like histamine (and mezcalin?), that otherwise does not show an affinity to PVP(6) and thereby further study the biochemical behavior of such peptide-like conjugated biogenic amines. Experiments in this direction that also include substances of the Arterenol-type, Serotonin, physiologically active amino acids and peptides such as thyroxin or peptide hormones should be conducted, as far as this is possible without much effort. ${ }^{4}$

The PVP-glycyl-L-leucyl-mezcaline derivative was obtained as described below (Scheme 1):

Scheme 1: Synthetic scheme for the synthesis of glycylleucyl-mescaline IV.

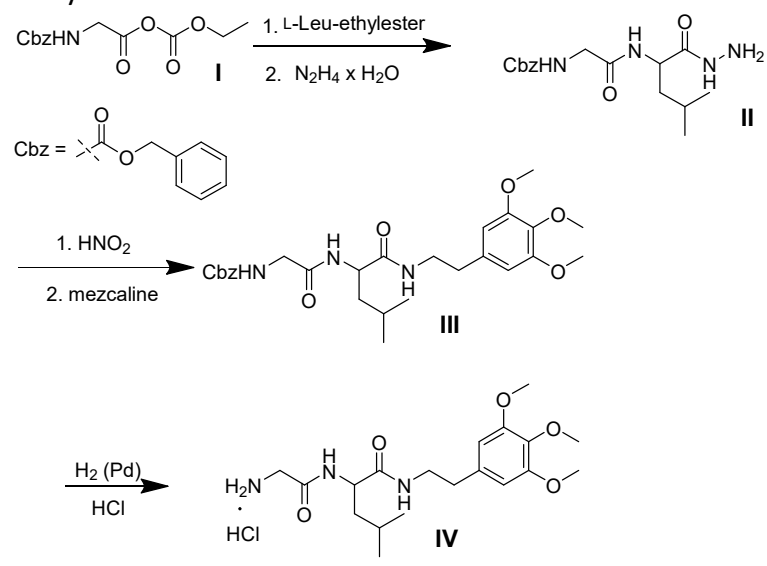

Box 2: In the 1940 and 1950ties, PVP was used as a plasma expander to after massive blood loss. This application of PVP has led to significant side effects, in the PVP storage disease leading to socalled pseudo-tumors, in which nonexcretable PVP is forming depots. It is now known that PVP of a molar mass $>20$ $\mathrm{kg} / \mathrm{mol}$ cannot be fully excreted. Of course, it is important to consider the dispersity of the polymer. At the time, only free radical polymerization was known, leading to products with a dispersity of PVP of about 2. Such polymer will contain a very significant portion of very high molar mass (see Tutorial Figure 1)

a) Synthesis of glycyl-L-leucyl-mezcaline hydrochloride

Following a method by Biossonnas(7), carbobenzoxy-glycin (Cbz-gly) was reacted with ethyl chloroformiate and the obtained the mixed anhydride I was reacted with L-leucine ethyl ester to obtained the corresponding dipeptide ester. This intermediate was without purification converted to the carbobenzoxy-glycyl-L-leucine hydrazide II using hydrazine hydrate ( $45 \%$ yield with respect to $\mathrm{Cbz}$-glycine). The product had a melting point of $125-127^{\circ} \mathrm{C}$. Via the corresponding azide and its reaction with mezcaline, carboxy-glycyl-L-leucyl-mezcaline (III), with a melting point of $127^{\circ} \mathrm{C}$ was obtained with $57 \%$ yield. Reductive elimination of the $\mathrm{Cbz}$ and treatment with hydrochloric acid yielded $94 \%$ of glycyl-L-leucyl-mezcaline-hydrochloride (IV), a colorless, glassy, very bitter tasting ${ }^{5}$ substance with [alpha] ${ }^{27} \mathrm{D}:-56.2 \pm 1^{\circ}(4.2 \%$ in water). Purity was verified using paper chromatography and elemental analysis.

b) Synthesis of a copolymer of vinyl pyrrolidone and acrylic acid.(8)

\footnotetext{
${ }^{2}$ Of course we have learned a lot about retention of (synthetic) macromolecules since Jatzkewitz' time. Retention in the blood stream and different organs depends on many different factors and the molar mass is only one of them. Charge, hydrophilicity/hydrophobicity, polymer architecture and hydrodynamic volume are others.

${ }^{3}$ Although it is unknown what Jatzkewitz is exactly referring to here, it seems apparent that this means to refer to non-covalent entrapment/binding of active substances in form of a complex or other non-covalent interactions.

${ }^{4}$ Although not mentioning small molecule drugs specifically, Jatzkewitz does suggest here a range of different pharmacologically acive substance, clearly pointing out the potential of this polymer-drug conjugate approach. ${ }^{5}$ back at this time, it was common to taste new compounds, this practice, of course, has been abandoned since.
} 


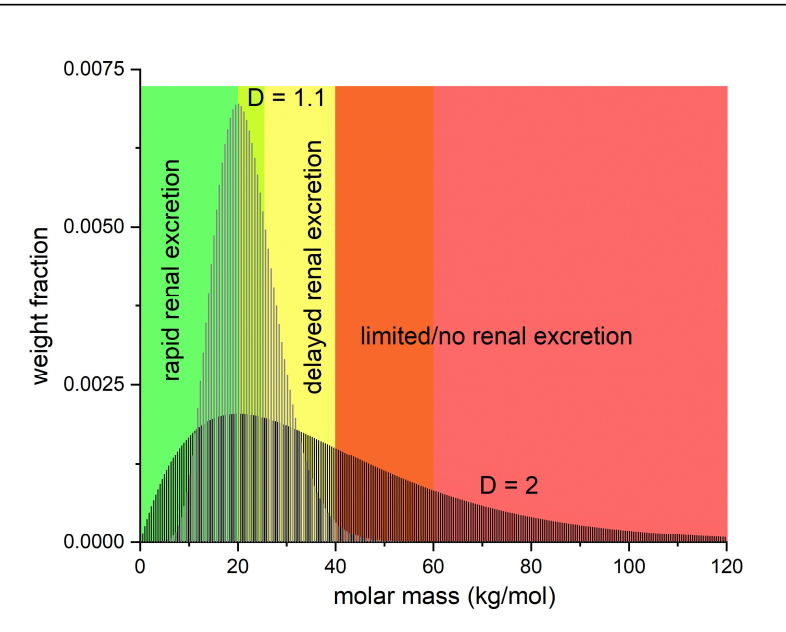

Tutorial Figure 1: Simulated PVP molar mass distribution for $M_{n}=20 \mathrm{~kg} / \mathrm{mol}$, presented as weight fractions obtained from Schulz-Zimm distribution functions. For the two different distributions, different chain coupling coefficients ( 1 (black) and 5 (grey), respectively) were used, resulting in dispersity values of 2 and 1.2, respectively. Regions which are expected to yield different extend of renal excretion are color coded. Polymer chains lying in the green area should be cleared rapidly via the kidneys, while polymers in the orange area will show delayed clearance. Polymer molecules that lie in the red area are expected to show very long retention or cannot be cleared at all via the kidneys.
$\mathrm{N}$-Vinylpyrrolidon ( $\mathbf{V}=\mathrm{VP})$ was copolymerized with $14 \%$ methyl acrylate (MA) (VI) using hydrogen peroxide and ammonia as initiators in water at approximately $100^{\circ} \mathrm{C}$ according to Puetzer and colleagues(9). The copolymer $\mathrm{P}(\mathrm{VP}-\mathrm{co}-\mathrm{MA})$ VII, constituting a gel, was saponified in aqueous sodium hydroxide at 20 ${ }^{\circ} \mathrm{C}$ and the low molar mass constituents removed by dialysis. The high molar mass hydrolyzed copolymer P(VP-co-AA $\left.{ }^{6}\right)$ VIII was obtained as a colorless powder in $73 \%$ yield (with respect to $\mathbf{V}+\mathbf{V I}$ ) which yields a clear aqueous solution. The $\mathrm{pH}$ value of an aqueous solution of $\mathrm{P}(\mathrm{VP}-\mathrm{Co}-\mathrm{AA})$ was found to be 5 . Titration using $\mathrm{n} / 10$ aqueous sodium hydroxide was employed to determine the amount of titratable carboxylic acids. Assuming that the polymer composition corresponded with the monomer composition, $86 \%$ of all ester groups were hydrolyzed ${ }^{7}$.

c) Conjugation of Glycyl-L-leucyl-mezcalin (IV = Gly-leu-mez) to P(VP-co-AA)

The conjugation of the mezcalin-dipeptide was performed, similar as the peptide coupling itself, using the method of

Scheme 2: Synthetic scheme for the preparation of mescaline polymer conjugate $\mathbf{X}$.

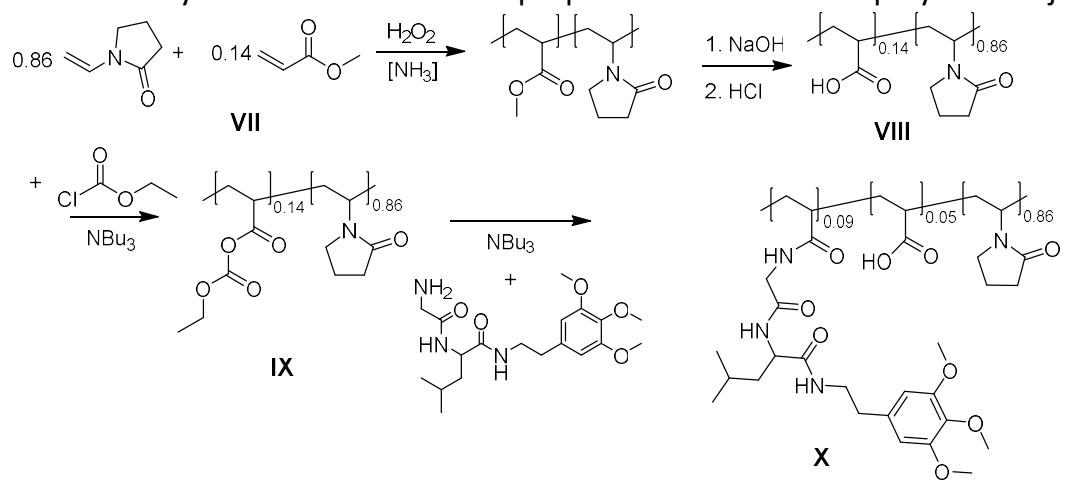

Biossonnas(7). The mixed anhydride of P(VP-co-AA) and ethyl chloroformiate was obtained in DMF using tributylamine as $\mathrm{HCl}$ scavenger. IX was obtained according to Scheme 2.

The PVP-mezcaline conjugate $\mathbf{X}$ was dialyzed against $\mathrm{n} / 40-\mathrm{HCl}$ and water to remove low molar mass impurities. The product contained still $37 \%$ of the original free carboxylic acids. With respect to VIII, the

\footnotetext{
${ }^{6}$ Through hydrolysis, the MA becomes acrylic acid, AA in short.

${ }^{7}$ For the sake of clarity, we draw the polymer to be fully hydrolysed in Scheme 2. However, the reader should keep in mind that in fact instead of 14 mol\% carboxylic acids, the polymer comprises on average 12 mol\% carboxylic acids and 2 mol\% methyl acrylate units (corresponding to $86 \%$ of hydrolysis). The non-hydrolysed methyl acrylate units naturally remain in the polymer throughout and exert their hydrophobic character.
} 
obtained yield was $50 \%$. The product is partially soluble in water, partially forming a fine, stable emulsion (Box 3).

Box 3: These short comments highlights the practical issues with the heterogeneity of the this first polymer-drug conjugate. Being synthesized through free radical polymerization, the polymer contains fractions that are significantly enriched in MA units (see also Box 4). While the synthesized polymer presents as a gel, the hydrolyzed polymer forms a clear solution by itself, as the acrylic acid units are of course hydrophilic when deprotonized. However, as they eventually end up conjugated with mezcaline, these repeat units again render the product water insoluble. On the other hand, the polymer contains fractions of polymer chains, which are basically PVP homopolymer, which may contain a few MA units. Accordingly, these polymers will end up with much fewer (if any) mezcaline molecules conjugated to it. Therefore, due to the synthetic limitations at the time, Jatzkewitz ends up with a rather insoluble polymer-drug conjugate fraction with a large amount of active component but poor solubility and a wellsoluble polymer-drug conjugate fraction with excellent solubility but very low (ca. $1 \%$ ) content of active component.

The successful conjugation of the mezcaline-peptide derivative to the copolymer was proven by paper chromatography and infrared spectroscopy.

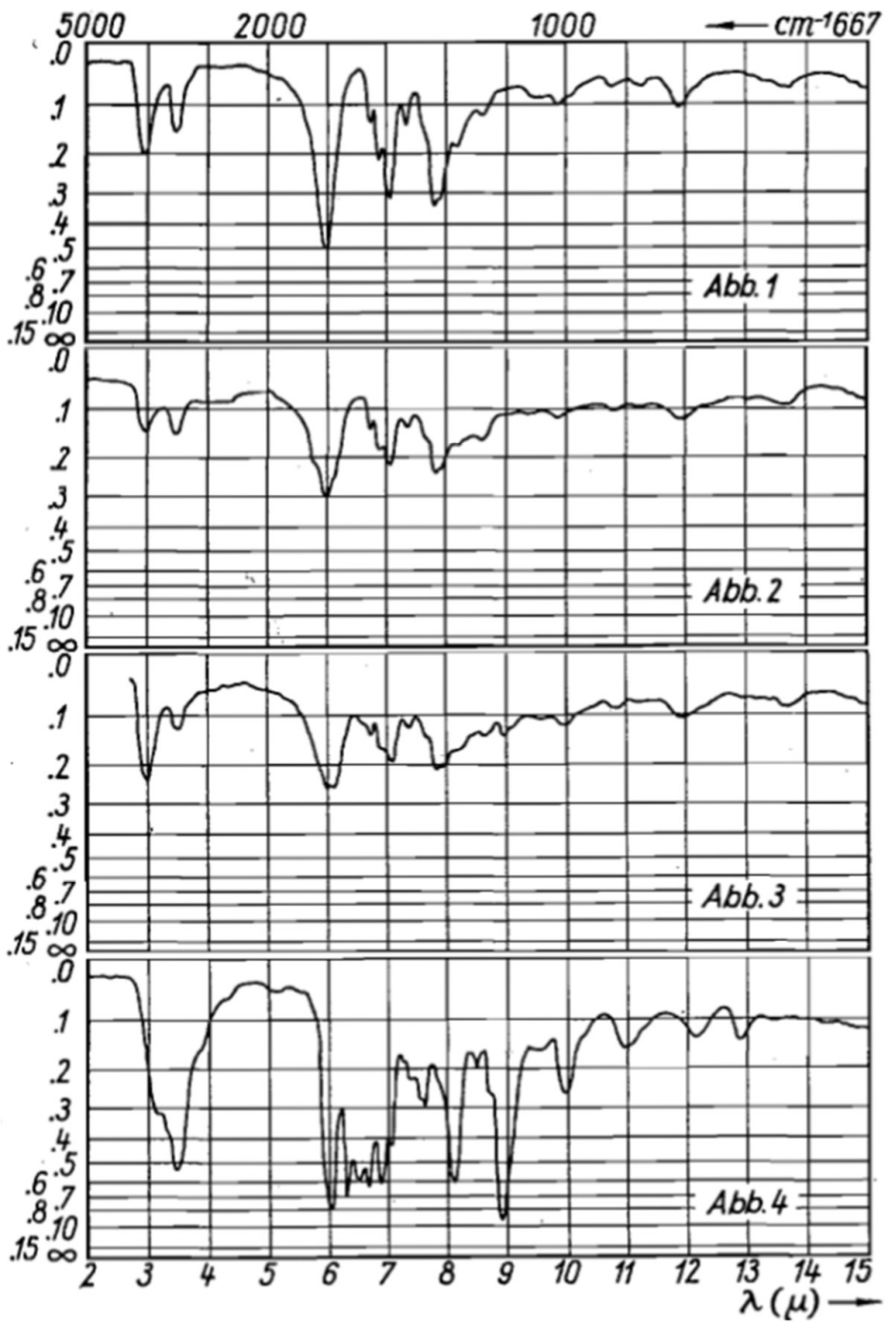

Figure 1: IR spectra of Abb. 1) Polyvinylpyrrolidone, Abb. 2) copolymer of vinyl pyrrolidone and acrylic acid VIII, Abb. 3) glycyl-L-leucyl-mezcaline, covalently attached to a copolymer of vinyl pyrrolidone and 
The high molecular mezcaline-polymer conjugate $\mathbf{X}$ was compared to a mixture of VIII and IV using paper chromatography in two solvent systems. The peptidic component was detected by ninhydrin only in the mixture. The polymer bound peptide give a positive ninhydrin test only after acidic hydrolysis. The mezcaline-peptide-polymer conjugate $\mathbf{X}$ was compared to the control polymer $\mathbf{V I I I}$, both were subjected to hydrolysis conditions and the product analyzed by paper chromatography. The mezcaline-peptide-polymer conjugate $\mathbf{X}$ yielded the glycine and leucine spot. In contrast, mezcaline was completely degraded under these conditions $\left(6 \mathrm{~N} \mathrm{HCl}, 115^{\circ} \mathrm{C}, 16 \mathrm{~h}\right)(10)$. The analysis of the infrared spectra of the four products, PVP (Fig. 1, Abb. 1), P(VP-co-AA) (Fig. 1, Abb. 2), X (Fig. 1, Abb. 3) and glycyl-leucyl-mezcalin HCl (Fig. 1, Abb. 4) yielded the following:

The IR spectra of the mezcaline-polymer conjugate (solid in $\mathrm{KBr}$ ) shows two bands in the $\mathrm{C}=\mathrm{O}$ region at 6.03 and $6.12 \mu^{8}$. The band at shorter wavelength is attributed to the carbonyl stretch band of the pyrrolidone moiety as the spectra of PVP show a band at the same position. At $6.12 \mu$, the $\mathrm{C}=\mathrm{O}$ stretch of the peptide carbonyl is observed. In the free glycyl-leucyl-mezcaline, this band is observed at $6.10 \mu$. Comparing the mezcaline ether band $(8.95 \mu)$ in the spectra of glycyl-leucyl-mezcaline and the polymer conjugate $\mathbf{X}$, one finds $9 \pm 2$ pyrrolidone moieties per peptide moiety. For comparison, using the percentage of converted carboxylic acids, a ratio of 10:1 was obtained.

As was mentioned before, the drug-peptide-polymer conjugate $X$ partially dissolves in water, but partially forms a milky emulsion. The emulsion can be precipitated by centrifugation at $30.000 \mathrm{rpm}$ for $15 \mathrm{~min}$. The supernatant contained $45 \%$ of the material as determined after removal of the water. The fraction did not contain free carboxylic acids and showed only about one tenth of the expected glycin and leucine content after acid hydrolysis ${ }^{9}$, as determined by paper chromatography. Moreover, the IR spectra resembled that of pure PVP. This shows that during copolymerization of VP and MAA, initially the acrylate polymerizes preferentially. There are several possibilities to prevent this and to adjust the monomer consumption. Experiments towards this end shall be conducted (Box 4).

$[\ldots]$

Acknowledgment and Experimental details are omitted in this translation but can be found in the original article.

$[\ldots]$

Summary

The synthesis of glycyl-L-leucyl-mezcaline is described. The mezcaline peptide derivative is convalently attached to a copolymer of vinylpyrrolidone and methyl acrylate. The conjugation was achieved through the carboxylates of the copolymer, which consists of $89 \%$ of vinylpyrrolidone repeat units. The possible relevance of the polymer-peptide conjugate as prototype of a class of enzymatically degradable, biologically active compounds, which can regulate the residence time of small bioactive molecules in the organism via attachment to polymers is noted.

Box 4: Indeed, the copolymerization parameters of $\mathrm{VP}\left(\mathrm{r}_{\mathrm{VP}} \approx 0.1\right)$ and $\mathrm{MA}\left(\mathrm{r}_{\mathrm{MA}} \approx 4-5\right)$ are vastly different, meaning that the MA polymerizes much faster compared to VP. This, in combination with the free radical polymerization leads to the situation that the polymers formed initially will contain much more MA that would be expected from the stoichiometry of the reaction, while the polymer chains formed later during the reaction will essentially be VP homopolymers, as most of the MA will already have reacted. In contrast, if this reaction were to be carried out using reversible deactivation radical polymerization, the resulting polymers would have a pronounced gradient or even pseudo-block copolymer architecture. In any case, this work shows very nicely how important it is to understand the polymerization kinetics and copolymerization parameters, when designing polymer drugconjugates.

\footnotetext{
8 please note, this is the wavelength of the IR-band in micrometer.

${ }^{9}$ please refer again to Box $\mathbf{3}$ in this context. As only one tenth of the amount of mezcaline is found and the initially hydrolyzed polymer contained $12 \%$ carboxylates, the soluble fraction contains only about $1 \%$ of mezcaline unis. At such low content, it is not surprising that the IR essentially resembles that of pure PVP.
} 


\author{
A blood plasma expander (poly vinylpyrrolidon) conjugated peptide-drug derivative (Glycyl-L-leucyl- \\ mezcalin) as novel depot for biologically active primary amines (mezcalin) \\ Horst Jatzkewitz, \\ Klinisches Institut der Deutschen Forschungsanstalt für Psychiatrie, München, Germany \\ Zeitschrift für Naturforschung 1955, 10, (1), 27-31.
}

Abstract: Mezcaline hydrochloride, glycyl-L-leucyl-mezcalin hydrochloride and a polymer conjugate of glycyl-L-leucyl-mezcaline to a copolymer of vinylpyrrolidone and acrylic acid (P(VP-co-AA)) was injected s.c. and i.p. At different time intervals, the basic degradation products (mezcaline) in the urine were quantified. The injected amount of mezcaline was equal $(1.7 \mathrm{mg})$ in all groups, so that the excretion of mezcaline correlates with the residence time of the biogenic amine in the organism. While the two low molar mass compounds were excreted within $16 \mathrm{~h}$, mezcaline could be detected even after 17 days after s.c. of the mezcaline-peptide-polymer conjugate. These findings are viewed in the light of pharmacology, pharmacy, biochemistry and psychiatry.

Mezcaline, the biogenic amine found in several cacti, is well known to cause psychological changes after administration to healthy humans which are similar to those found in some psychoses(11). Block and coworkers found that a fraction of the applied mezcalin is incorporated into a liver protein $(3,4)$. About $80 \%$ of the applied dose is excreted via renal excretion unmetabolized, as both mice and human can metabolize mezcalin only poorly. The product of the incorporation into the liver proteins was not isolated nor characterized in more detail.

Inspired by this investigation we have prepared a peptide-drug conjugate - glycyl-L-leucyl-mezcaline, as described previously(12). Furthermore, to make it more protein-like, we have covalently conjugated it to a colloidal plasma expander, namely a copolymer of vinylpyrrolidone and acrylic acid (P(VP-co-AA)) with a broad molar mass distribution ${ }^{10}$. Both peptamine as well as the polymer conjugate (I, see Scheme 1 ) were synthesized to gain insight into the biochemical behavior of peptide-like conjugates of native/biogenic physiologically active compounds of the primary amine type ${ }^{11}$. It was assumed that I may represent a novel depot form for primary amines. In the present second communication, this hypothesis is being tested and fully verified.

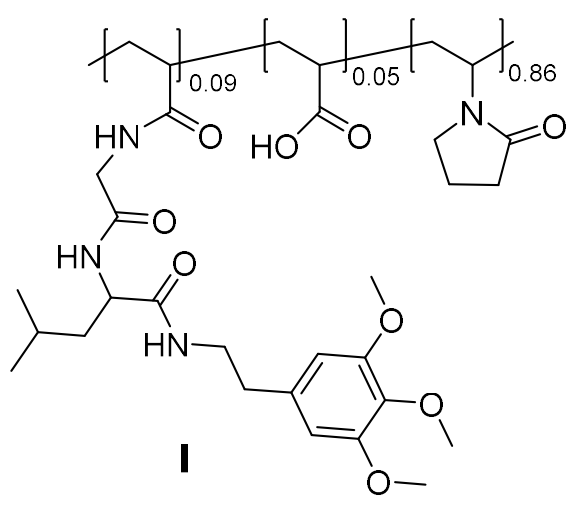

Scheme 1: Structure of the polymer conjugate I, prepared by conjugation of glycyl-L-leucyl-mezcaline peptamin and P(VP-co-AA)(12).

\footnotetext{
${ }^{10}$ this is of course quite the opposite of "protein-like" as proteins do not suffer from any molar mass distribution

${ }^{11}$ here Jatzkewitz presumably refers to substances such as dopamine or other chatecholamines such as adrenaline
} 
The hypothesis is based on the fact that $\mathbf{I}$ is a conjugate of a non-physiological, high molar mass carrier, which guarantees a long residence time in the organism, to which the active compound is bound via a physiological linker, i.e. a dipeptide. The active compound should therefore be enzymatically released in the living organism, if the peptamine is cleaved in vivo ${ }^{12}$.

To investigate this, white mice were injected s.c. and i.p. with i) $2 \mathrm{mg}$ of mezcaline hydrochloride $(\mathrm{mez}-\mathrm{HCl})$, ii) $3.4 \mathrm{mg}$ (glycyl-L-leucyl-mezcalin-hydrochloride (gly-leu-mez-HCl), iii) a mixture of the macromolecular carrier (P(VP-co-AA)) (16 mg) and $3.4 \mathrm{mg}$ of gly-leu-mez-HCl, iv) $20 \mathrm{mg}$ of the macromolecular linker with a biodegradable linker (I) and v) $24 \mathrm{mg}$ of a conjugate with a non-degradable linker (P(VP-co-AA-co-mez)). ${ }^{13}$ All substances yield clear solutions in water at neutral $\mathrm{pH}$. The amount injected was chosen so that all animals received $1.7 \mathrm{mg}$ mezcalin. The basic excretion products in the animal's urine were analyzed at different time intervals, for which we used the paper chromatographic analysis method for basic addictive drugs developed by us(13). This method is not quantitative but does reflect the quantitative ratio [between different groups] well, if all parameters are kept constant.

\section{Methods}

$[\ldots]$

Experimental details are omitted in this translation but can be found in the original article.

$[\ldots]$

\section{Results}

From the ascending paper chromatograms of the extracts of the white mice's urine after s.c. injection (Fig. 1), the following is apparent:

1. Mezcaline is the only basic metabolite detected if mezcaline or mezcaline-peptamine was administered.

2. If one compares the amounts of excreted mezcaline in the urine pooled for 4 hours after injection of mezcaline and mezcaline-dipeptide, no difference is observed. After $16 \mathrm{~h}$ (urine pooled $16-20 \mathrm{~h}$ p.i.), the excreted amount is below the detection limit (3 $\mathrm{\gamma})$.

3. Also after injection of a mixture of mezcaline-dipeptide and P(VP-co-AA) no significantly different result is obtained. After $16 \mathrm{~h}$, the amount of mezcaline falls below the detection limit.

4. The polymer conjugate I however, showed and entirely different excretion profile: Using the crude polymer, mezcaline is excreted continuously over 17 days in the $24 \mathrm{~h}$ pooled urine (average of 5 animals, in 4 the amount was below detection limit after 17 days, in one animal after 21 days.) after s.c. injection. Initially about 15 y are excreted, overall not more than $250 \gamma$.

5. Investigating the direct conjugate without the biodegradable linker, no basic excretion products are detected (data not shown).

\footnotetext{
12 notably, Jatzkewitz here clearly introduces the concept of a physiologicially cleavable linker between drug and carrier, necessary for the release of he active component. This is probably the first mentioning of the polymeric pro-drug concept still at the core of some many research projects today.

${ }^{13}$ the selection of different compounds is an excellent showcase how to select control experiments. Free drug, free drug plus polymer (non-conjugated) and polymer-drug conjugate with a non-cleavable linker would also today be still considered the ideal choice of control experiments to verify the presented hypothesis.
} 


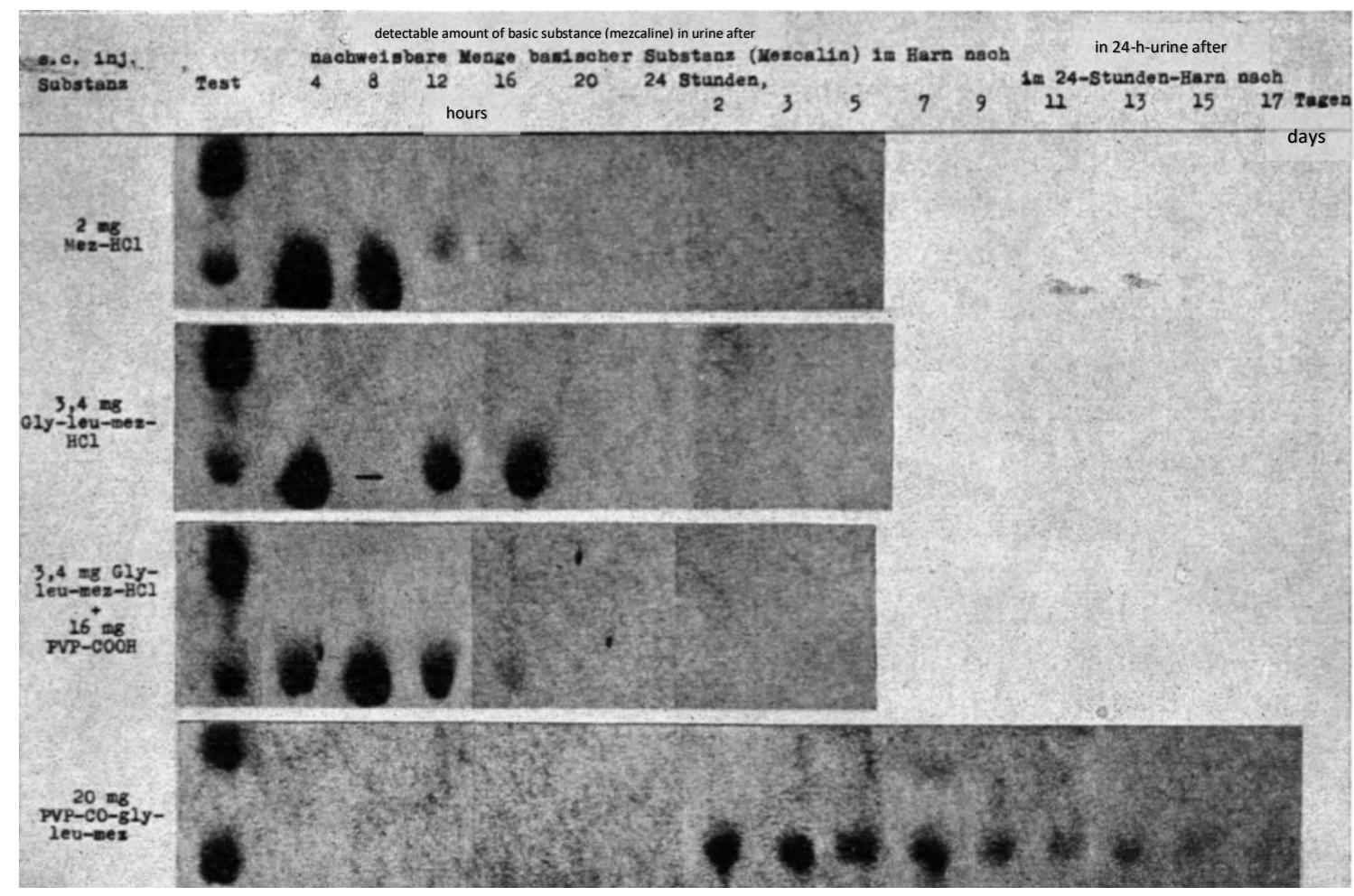

Figure 1: Cut-outs from ascending paper chromatograms of urine extracts of a white mouse after s.c. injection of different mezcaline-containing substances with $1.7 \mathrm{mg}$ mezcaline equivalents. (Test: lower spot $=20$ y Mez, upper spot $=30$ y gly-leu-mez; $-=$ no urine obtained.)

The described data refer to s.c. injection. After i.p. injection, all substances give similar excretion patterns with the exception of the conjugate I. For the latter, while the total amount of excreted mezcalin was similar, the amount of excreted mezcalin dropped below detection limit already after 9 days ${ }^{14}$ (average of 3 animals, all gave negative result after 9 days). An estimate on the toxicity of the injected substances can be find in Table 1.

Animals that received I were sometimes languid. The non-surviving animals died 1-3 days p.i. Three animals were investigated post mortem by Dr. Herz, Pharmacological Institute of the University Munich. The only pathological change found was a pleural exudate.

The conjugate I exhibits a considerable toxicity upon i.p. injection (Table 1).

Table 1: Mortality of white mice (37-42 g bodyweight) after s.c. and i.p. injection of different mezcaline containing substances with a mezcaline (mez) content of $1.7 \mathrm{mg}$.

\begin{tabular}{l||l|l|l|l|l} 
Injected substance & $\begin{array}{l}\# \text { animals } \\
\text { injected s.c. }\end{array}$ & $\begin{array}{l}\# \text { animals } \\
\text { died thereof }\end{array}$ & $\begin{array}{l}\# \text { animals } \\
\text { injected s.c. }\end{array}$ & $\begin{array}{l}\# \text { animals } \\
\text { died thereof }\end{array}$ \\
\hline \hline $2 \mathrm{mg} \mathrm{mez-HCl}$ & 4 & 0 & 10 & 1 \\
\hline $3.4 \mathrm{mg}$ gly-leu-mez-HCl & 5 & 0 & 4 & 1 \\
\hline $3.4 \mathrm{mg}$ gly-leu-mez-HCl + 16 mg PVP-COOH & 4 & 0 & 8 & 2 \\
\hline $20 \mathrm{mg}$ PVP-CO-gly-leu-mez I & 7 & 2 & 11 & 8 \\
\hline $24 \mathrm{mg}$ PVP-CO-mez & 10 & 2 & 11 & 5
\end{tabular}

\footnotetext{
${ }^{14}$ This observation most likely reflects that he fact that i.p. leads to a faster uptake into the bloodstream as compared to s.c. administration
} 


\section{Discussion}

Looking at the obtained results with respect to the most important substance described herein, the polymer-peptamine conjugate $\mathbf{I}$, it is clear that the physiologically active constituent of $\mathbf{I}$, the gly-L-leu-mez is metabolized so quickly, that it seems unlikely that its physiological activity would differ from mezcalin. This corroborates earlier finding by others.

Guggenheim described in 1913 that glycyl-tyramine and glycyl-histamine act like the free amines but are less toxic.(14) He assumed that the peptamine is metabolized in the animal organism. The correctness of this assumption was later confirmed, when Abderhalden found that D,L-leucyl-tyramine is cleaved asymmetrically by intestinal and pancreatic fluids.(15)

Furthermore, our results show that the in vivo cleavage of mezcaline from the peptamine, as mentioned initially, is a prerequisite for the specific enzymatic degradation, and therefore, the ability of $\mathbf{I}$ to act as a depot. Without the biodegradable linker, no mezcalin can be detected in the urine of the treated animals.

Regarding the mechanism of action, two possibilities appear reasonable.

1. Mezcalin is cleaved from I as fast as it is cleaved from gly-L-leu-mez while the high molar mass carrier, which comprises $89 \%$ from poly(vinylpyrrolidone) (PVP)(12), constitutes the depot due to is special interaction with basic substances. In this case, co-injection of the carrier and the unbound peptamine should result in the same rate of mezcaline excretion. This is not the case (Fig. 1). Similar to histamine, mezcaline shows no affinity to PVP(6) and it remains only the alternative described below.

2. The enzymatic release of mezcalin from the polymer occurs slowly over the course of days.

In the latter case, the cleavage should be dependent, inter alia, on the resorption. The resorption, on the other hand, depends, among other parameters, on the molar mass of the injected substance as well as the route of administration. Therefore, the different mezcaline excretion between s.c. injection and i.p. administration can be understood. By determination of location and kind of enzyme (proteinase?, peptidase?) the circumstance could be understood in detail.

The resorption may also be responsible for the observation that only $15-20 \%$ of the administered mezcalin was excreted as free mezcalin, while Block $(3,4)$ found $80 \%$ excreted in the urine after injection. However, it is also possible, that the degree of detoxification is higher with prolonged exposure of smaller doses. It may be particularly interesting for the pharmacist and the pharmacologist whether the toxicity of I upon i.p. injection is due to the fact that this administration mimics a continuous i.v. injection or due to the properties of the injected polymer conjugate $\mathbf{I}$. The comparison of the toxicity between $\mathbf{I}$ and the nonbiodegradable conjugate should inform about this, because I and the non-degradable conjugate only differ in its enzymatic degradability. Table 1 only approximates the actual toxicities but it appears reasonable to state that the macromolecular component significantly adds to the toxicity of the conjugates. In any case, it plays an important role, in particular from a pharmaceutical point of view. Apart from the fact that the components of the carrier may be detrimental for the organism, macromolecules that exceed a certain size cannot be eliminated from it.(5) This is likely the case for a part of the polymer conjugate synthesized by us, as the constituent polymer certainly suffers from a broad molar mass distribution (Box 5). On the other hand, it is necessary that a certain minimum molar mass is exceeded to enable a prolonged residence time in the organism which is necessary to allow a form of depot effect. Therefore, a suitable fractionation of the molar mass distribution and a suitable drug loading (which, in our case, should be readily achieved by variation of the acrylic acid content of the copolymer $)^{15}$ with a suitable drug will likely to govern the pharmaceutical

Box 5: Gel permeation chromatography was not available at this time, but Jatzekwitz is certainly correct to assume the polymers will have likely have a dispersity of around 2, typical for free radical polymerization (see also Tutorial Figure 1), even though no characterization was included in this respect. aspects. This suitable drug could also be an endogenous compound of the primary amine type, for example the biogenic amines histamine, arterenol and serotonin, the physiologically active amino acid thyroxin or

${ }^{15}$ However, the problem of the vastly different copolymerization parameters of VP and AA would still remain. 
the peptide hormone of the posterior pituitary oxytocin or vasopressin. Hence, we transition to the viewpoint of the biochemist, who will view the macromolecular carrier as a protein of low component yield $^{16}$ and mezcaline as one of the mentioned components of the primary amine-type. The biochemist will ponder the question, whether I is a model for the "bound form" of histamine or for van Dyke's $(16)$ "motherprotein" of the hormones found in the posterior pituitary or whether biogenic amines and peptide hormones are incorporated this tightly into suitable proteins or cellular structures without covalent bonds. An answer to this question cannot be given to date and is not expected from the biochemical mechanism of model substances. It can only be shown that the known biochemical mechanism, i.e. that an inactive precursor (e.g. pro-enzyme, hypertensinogen ${ }^{17}$, fibrinogen) of a physiological active substance is activated through an enzyme, is also transferable to biogenic amines, possibly also to peptide hormones in the combination with proteins ${ }^{18}$. Therefore, when assessing the biological activity of bound forms, the factor time needs to be considered. The issue, that biogenic amines are active in the combination with proteins, possibly in a modified manner, is also interesting in a different context.

It is known, that certain basic substances, including biogenic amines, can elicit psychological changes in humans which are similar to some forms of schizophrenia. Hence, Buscaino et al.(17) attribute toxic substances of basic nature which are presumably formed in a derailed metabolism, to be responsible for the formation of these mental disorders and Woolley et al.(18) recently considered lower levels of the endogenous biogenic amine serotonin as cause. Therefore, if one is searching for basic compounds in schizophrenic patients, one shall not forget proteins, into which these compounds may be incorporated. By administration of a depot-serotonin according to the present contribution, one may test Wooley's hypothesis.

It will be very difficult to successfully address the problem of the somatology of psychological disorders as long as it remains an equation with multiple unknowns. One may eliminate one unknown using a pharmacological approach with substances, which interfere with the psyche through the soma just as mezcaline does.

In contrast to those of mezcaline, the properties of I would allow us to single-out an issue within a more complex problem. While mezcaline elicits an acute intoxication, I allows eliciting an chronic intoxication in humans. While the acute mezcaline intoxication generally does not cause psychological damage, it would be important to know how long it takes a human, who is psychologically disturbed for 14 days by administration of $\mathbf{I}$, to return to mental equilibrium. However, also the answer to this question by experiment seems daring at this point and has to be left the psychologist at this point. ${ }^{19}$

Translation and comments by

Prof. Dr. Robert Luxenhofer

Functional Polymer Materials

At the Chair for Advanced Materials Synthesis

Department Chemistry and Pharmacy

Julius-Maximilians-University Würzburg

97070 Würzburg

Soft Matter Chemistry

Department of Chemistry

Helsinki University

00014 Helsinki

Röntgenring 11

Germany

\footnotetext{
${ }^{16}$ this is a direct translation of the original, which reads ,im makromolekularen Träger ein Protein von geringem Baustein-Umsatz [...] sieht." The author of this translation is not quite sure what this is supposed to mean in this context.

${ }^{17}$ hypertensinogen is today called angiotensinogen

18 again, here Jatzkewitz pioneers the idea of a polymeric prodrug.

${ }^{19}$ of course it is quite safe to assume, that such experiment would not be allowed by any ethics committee.
} 


\section{References}

1. Jatzkewitz, H., and Noeske, H.-D. (1951) Synthese des 3.5-Dijod-4-methoxy- $\beta$ phenäthylamins. Hoppe-Seyler's Zeitschrift für physiologische Chemie 287, 43-46

2. Block, W., Block, K., and Patzig, B. (1952) Physiology of the 14-C radioactive mescaline in animal experiment. I. Fermental experiments and excretion products. HoppeSeyler's Zeitschrift für physiologische Chemie 290, 160

3. Block, W., Block, K., and Patzig, B. (1952) Physiology of the $14 \mathrm{C}$ radioactive mescalin in the animal experiment. III. Addition of mescalin to liver protein. Hoppe-Seyler's Zeitschrift für physiologische Chemie 291, 119

4. Block, W. (1953) Über den fermentativen Einbau biogener Amine in Proteine. In vivound in vitro-Versuche mit $14 \mathrm{C}$ radioaktivem Mescalin und $14 \mathrm{C}$ radioaktivem $\beta$ Phenyläthylamin. Angewandte Chemie 65, 241-242

5. Weese, H. (1952) Therapeutische Möglichkeiten mit Blutersatzstoffen. in Bayer. Chirurgentagung, Munich

6. Reppe, W. (1954) Polyvinylpyrrolidon, Verlag Chemie GmbH, Weinheim/Bergstr.

7. Boissonnas, R. A. (1951) Une nouvelle méthode de synthèse peptidique. Helvetica Chimica Acta 34, 874-879

8. Breitenbach, J. W. (1953). Österr. Chemiker-Ztg. 54, 151

9. Puetzer, B., Katz, L., and Horwitz, L. (1952) Preparatory Method for N-Vinyl-2pyrrolidone. Journal of the American Chemical Society 74, 4959-4960

10. Schramm, G., and Braunitzer, G. (1950) Die Adsorptionsanalyse der Aminosäuren. Zeitschrift für Naturforschung B 5, 297-306

11. Beringer, K. (1927) Der Mezcalinrausch, J. Springer, Berlin

12. Jatzkewitz, H. (1954) Über den Einbau physiologisch wirksamer Substanzen in ein kollodiales Blutplasma-Ersatzmittel. Hoppe-Seyler's Zeitschrift für physiologische Chemie 297, 149-156

13. Jatzkewitz, H. (1953) Ein klinisches Verfahren zur Bestimmung von basischen Suchtmitteln im Harn. Hoppe-Seyler's Zeitschrift für physiologische Chemie 292, 94100

14. Guggenheim, M. (1913). Biochem. Z. 51, 372

15. Abderhalden, E. (1927). Fermentforsch. 9, 252

16. van Dyke, H. B., Chow, B. F., Greep, R. O., and Rothen, A. (1942) The isolation of a protein from the pars neuralis of the ox pituitary with constant oxytocic, pressor and diuresis-inhibiting activities. Journal of Pharmacology and Experimental Therapeutics 74, 190-209

17. Keup, W. (1954). Mschr. Psychiat. Neurol. 128, 70

18. Woolley, D. W., and Shaw, E. (1954) A BIOCHEMICAL AND PHARMACOLOGICAL SUGGESTION ABOUT CERTAIN MENTAL DISORDERS. Proceedings of the National Academy of Sciences 40, 228-231 